\title{
Atenolol prevents the formation of expansive hematoma after rhytidoplasty
}

\section{O atenolol previne a formação de hematoma expansivo após ritidoplastia}

\author{
Amanda Castilho Moreira ${ }^{1}$; Marcio Moreira ${ }^{2}$; Sanderland José Tavares Gurgel2; Yasmin Castilho Moreira ${ }^{2}$; Eguimar Roberto \\ Martins²; Raphael Chalbaud Biscaia Hartmann²; Dualma José Fagundes, TCBC-SP3
}

A B S T R A C T

\begin{abstract}
Objective: To evaluate the perioperative use of atenolol in reducing the incidence of hematoma after rhytidoplasty. Methods: Between January 2007 and February 2013, 80 patients were randomized into two groups: Group A $(n=26)$ received perioperative atenolol in order to maintain heart rate (PR) around 60 per minute; Group B ( $n=54)$ did not receive atenolol. Both groups underwent the same anesthetic and surgical technique. We monitored blood pressure (BP), HR, hematoma formation and the need for drainage. Patients were followed-up until the 90th postoperative day. The variables were compared between the groups using the ANOVA test. Continuous variables were presented as mean \pm standard deviation and the differences were compared with the Student's t test. Values of $p d^{\prime \prime} 0.05$ were considered significant. Results: In group A the mean BP $(110-70 \mathrm{mmHg} \pm 7.07)$ and HR $(64 / \min \pm 5)$ were lower $\left(p d^{\prime \prime} 0.05\right)$ than in group $B(135-90 \mathrm{mmHg} \pm 10.6)$ and $(76 / \mathrm{min} \pm 7.5)$, respectively. There were four cases of expansive hematoma in group B, all requiring reoperation for drainage, and none in group A ( $\left.p d d^{\prime \prime} 0,001\right)$. Conclusion: The perioperative use of atenolol caused a decrease in blood pressure and heart rate and decreased the incidence of expanding hematoma after rhytidectomy.
\end{abstract}

Key words: beta adrenergic antagonists. Ischemia. Hematoma. Rhytidectomy. Face.

\section{INTRODUCTION}

O ne of the major postoperative complications of rhytidectomy is the expansive hematoma. Its occurrence can reach up to $16 \%{ }^{1}$ and affects postoperative recovery, is associated with increased swelling and bruising and, in some cases, can lead to ischemia, infection, and necrosis of the operating area ${ }^{2}$. Furthermore, the extension of healing time (inflammatory phase) predisposes to cicatricial changes such as hyperpigmentation, scar hypertrophy, keloid formation and scarring in the subcutaneous tissue.

After revision of 1,078 rhytidectomies, the occurrence of expansive hematoma was attributed to several factors: plication and / or detachment of the platysma, high systolic blood pressure, male gender, use of aspirin and / or anti-inflammatory agents, and smoking ${ }^{3}$.

Many surgical approaches have been suggested for the prevention of this complication, most only of local action, such as external stitches ${ }^{2}$, use of suction drains ${ }^{4}$, tumescent infiltration ${ }^{4}$, tissue glues ${ }^{5}$, dissection with ultrasonic instruments ${ }^{6}$ and internal adhesion stitches ${ }^{7}$.

The occurrence of hematoma associated with high systolic blood pressure, nausea, vomiting, agitation, anxiety and pain has been repeatedly reported ${ }^{8,9}$. Nonsurgical preventive measures to control this manifestation were suggested, but only during the first 24 hours ${ }^{10}$.

Most patients of cosmetic surgeries are or becomes anxious (because of the surgical procedure itself), which, in general, increases heart rate (HR) and systolic blood pressure. In addition, most patients seeking facial rejuvenation have increased blood pressure levels (BP) due to the age.

Thus, we have decided to use the beta-blocker atenolol since the preoperative period and keep it until the 15th day postoperatively (PO) and associate its use to preventive measures, following a protocol of clinical care in a group of selected patients and compare them to a control group submitted to the same protocol, but without the drug atenolol, whether per- or postoperatively.

\section{METHODS}

After approval of the Ingá Faculty (Uningá) Ethics Committee, we randomly and prospectively selected 80 patients undergoing rhytidectomy in the Maringá Plasticlínica (Paraná State - PR, Brazil) between January 
2007 and February 2013. There was no restriction of range age. Inclusion criteria were: men or women who needed facelift without distinction of ethnicity or age. Exclusion criteria were: coagulation disorders, use of anticoagulants, smoking, routine use of beta-blockers and decompensated hypertension. The preoperative preparation followed a strict clinical routine, detailed analysis of the drugs in use, with attention to morbid or allergic history, laboratory tests, pre-anesthetic consultation and photographic documentation. We divided the patients into two groups: Group A (study), which preoperatively received oral atenolol at a single dose of 25 to $100 \mathrm{mg} /$ day for enough time to HR be maintained at 60 beats / min or less; and Group B (control), which received no medication. The protocol of per- and postoperative care was applied to both groups.

The surgical procedure took place under local anesthesia with sedation and spontaneous ventilation. Cardiovascular monitoring was performed with a heart monitor, and the respiratory, with pulse oximetry. We used $0.5 \%$ lidocaine with 1: 400,000 epinephrine for infiltration in a dose of $10 \mathrm{mg} / \mathrm{kg}$. The anesthetic sedation started after nasal inspection and use local vasoconstrictor. It was carried out with midazolam 2-15mg total dose; Propofol $30 \mathrm{ml} / \mathrm{h}$ was given by infusion pump, plus $3 \mathrm{ml}$ IV bolus when needed; 5-15mg total dose ketamine; Fentanyl $(25 \mathrm{mcg}) 0,5-1,5 \mathrm{ml}$ total dose; clonidine $(75 \mathrm{mcg}) 0.5 \mathrm{ml}$ in the beginning and $0.5 \mathrm{ml}$ more at the end of the operation should BP be over 120 / 80 mmHg; a \#7 nasopharyngeal tube was used after prior lubrication with $20 \%$ lidocaine gel. We also used a urinary Foley catheter for continuous drainage of urine. We used tramadol $50 \mathrm{mg}$ IV for analgesia, the antiemetics bromopride $2 \mathrm{ml}(5 \mathrm{mg} / \mathrm{ml}) \mathrm{IV}$ and ondansetron ( $2 \mathrm{mg} / \mathrm{ml}$ ) $4 \mathrm{ml} \mathrm{IV}$ and low molecular weight anticoagulant enoxaparin $0.4 \mathrm{ml}(40 \mathrm{mg}) \mathrm{SC}$ at the end of the operation and $18-23 \mathrm{mmHg}$ anti-thrombus elastic stocking.

The procedures used to rejuvenation were: conventional facelift with temporal-precapillary incision; preauricular-pre-tragus and retroauricular pre- and transcapillary, detachment of the skin flaps and frontal (superior) and slightly oblique traction of these flaps with plication of the SAMS (Superficial Aponeurotic Muscle System). Furthermore, we held blepharoplasty by the classical technique and application of fractional $\mathrm{CO}_{2}$ laser in the central region of the face in three passes with 15 mega joules (MJ) energy in the non-detached area and one pass with $10 \mathrm{MJ}$ in the detached region. The procedures were strictly the same in both groups and the mean operation time was four hours. Hemostasis was strict using electrocautery. We used a continuous aspiration 3.2 JacksonPratt drain for 24 hours and an occlusive and lightly compressive dressing with absorbent cotton and bandage. In the immediate postoperative period, sub-lingual captopril $50 \mathrm{mg}$ was used when the systolic pressure was greater than $120 \mathrm{mmHg}$. Analgesia was applied with dipyrone 500 mg / ml IV q.i.d., antiemesis with bromopride $2 \mathrm{ml}$ (5 $\mathrm{mg} / \mathrm{ml}$ ) for IV t.i.d. and ondansetron $4 \mathrm{ml}(2 \mathrm{mg} / \mathrm{mL}$ ) IV b.i.d., and levomepromazine $25 \mathrm{mg}$ in the form of sub-lingual drops when needed. The hospital stay was 24 hours.

After discharge and drian removal, patients were instructed not to do any physical activity, nor flex or twist the neck, apply ice packs on the face $4 x$ / day and to remain with a small occlusive dressing at home until the third PO day, when all the bandages were removed in the clinic. The postoperative follow-up occurred on the fifth, tenth, 15th, 30th, 60th and 90th days for local and general evaluations and provision of new directions for both groups. Patients in group A maintained the use of atenolol until the 15th postoperative day.

The parameters evaluated were: $\mathrm{BP}, \mathrm{HR}$, presence of hematoma and the need for surgical drainage of expansive hematoma. On the first day, the assessments were made one at a time with the aid of specialized nursing.

The recovery time for each patient was evaluated on an outpatient basis by the same medical team, from the immediate PO (in-hospital) until the 90th day.

Variables were compared between the groups using the ANOVA test. Normal variables were presented as " $\mathrm{N}$ " (\%) and the differences were compared using the Student's $t$ test. Values of $p d^{\prime \prime} 0.05$ were considered significant.

\section{RESULTS}

Data regarding the frequencies of gender, age, mean and standard deviation of $\mathrm{BP}, \mathrm{HR}$, presence of hematoma and need for drainage are shown in table 1.

Twenty-six patients were allocated to group $A$ (study) and 54 patients to group $B$ (control). In group $A$, the mean BP in the first day was $110-70 \mathrm{mmHg}$ and $\mathrm{HR}$ was 64 / min. In the evaluations of the third day they remained the same. In the fifth, tenth and fifteenth days they were $120-80 \mathrm{mmHg}$ and $60 / \mathrm{min}$, and evaluations of 30 and 60 days showed 130-90 $\mathrm{mmHg}$ and 74 / min, respectively.

There was no expansive hematoma in any of the evaluated moments (first, third, fifth, tenth, 15th, 30th, 60th and 90th days). In only one case there was a left retroauricular seroma, which was drained with a fine needle aspiration on the tenth day.

The mean recovery time was considered normal by the team. All patients were already moving the neck normally after 15 days and returned to normal activities between 15 and 30 days. After the 60th day, they were released to daily physical activities and showed no edema or any change in skin, nor scars.

In group $B$, the average BP on the first day 135$90 \mathrm{mmHg}$, and HR, 76 / min. Six patients had BP peaks of $150-100 \mathrm{mmHg}$ and had to receive sub-lingual captopril to control them. There were three expansive unilateral hematomas (two female patients and one male) that were drained in the operating room with sedation in the 
Table 1 - $\quad$ Results (values) obtained (Mean \pm SD) after rhytidectomy in 80 patients observed for 90 days.

\begin{tabular}{lll}
\hline & $\begin{array}{l}\text { Group A (26) } \\
\text { Atenolol }\end{array}$ & $\begin{array}{l}\text { Group B (54) } \\
\text { Control }\end{array}$ \\
\hline Age (Mean) & $51.5( \pm 6.9)$ & $54.2( \pm 8)$ \\
Gender & Female: $25=96.15 \%$ & Female: $52=96.3 \%$ \\
& Male: $1=3.85 \%$ & Male: $2=3.7 \%$ \\
Blood pressure (Average) & $110-65 \mathrm{mmHg}( \pm 7.07)$ & $135-90 \mathrm{mmHg}( \pm 10.6)$ \\
Heart Rate (Average) & $64 / \mathrm{min}( \pm 5)$ & $76 / \mathrm{min}( \pm 7.5)$ \\
Expansive Hematoma & 0 & $4=7.4 \%( \pm 25)$ \\
Reoperation for drainage of hematoma & 0 & $4=7.4 \%( \pm 25)$ \\
\hline
\end{tabular}

Blood pressure (Average): Group A $<$ Group B $(p<0.05)$;

Pulse Rate (Average): Group $A<\operatorname{Group} B(p<0.05)$;

Expansive hematoma: Group $A<$ Group $B(p<0.001)$;

Reoperation for drainage of hematoma: Group $A<$ Group $B(p<0.001)$

immediate postoperative period between six and seven hours after the operation. The mean BP in the third, fifth and tenth days was $140-100 \mathrm{mmHg}$ and, from the 15th day on, $130-90 \mathrm{mmHg}$. The average HR in the third, fifth, tenth and fifteenth day was 72 / min.

One female patient had a hypertensive crisis in the 12th postoperative day, with BP levels of $180-120 \mathrm{mmHg}$ and HR 98 / min, and developed a large late unilateral hematoma, requiring immediate surgical drainage.

The recovery time of patients in group $B$ (control) who did not display expanding hematoma was similar to group A (Atenolol). However, the two patients with expanding hematoma in the immediate postoperative period who belonged to group B had a slight delay in healing on the affected side due to epitheliolisys of the edge of the flap and had prolonged edema. The patient with late expansive hematoma had necrosis of the skin flaps of the retroauricular portion on the affected side and she only returned to normal activities after 90 days postoperatively. Because of the prolonged edema, epithelialization occurred definitively only after 90 days. Two surgical procedures were needed for correction of the scar on the sixth and twelfth months.

\section{DISCUSSION}

There is no consensus about the best anesthesia to be used for a facelift. Several authors use general anesthesia in their services $3,4,8,10$. The anesthesia performed in this study was sedation associated with local infiltrative anesthesia with lidocaine, also used by other authors ${ }^{2,11}$. Endotracheal intubation and reflexes triggered by general anesthesia can cause arrhythmias, reflex hypertension and bleeding, with hematoma formation. Adequate control of these reflexes can be obtained using atenolol, as has been shown in some studies ${ }^{12,13}$. Despite this, we still prefer the technique of local anesthesia with sedation, which proved to be safe and effective. There were no complications related to this technique. Whereas the operated patients are of more advanced age and usually have cardiovascular or metabolic comorbidities, using general anesthesia should be questioned. A comparison between the technique of local anesthesia + sedation with general anesthesia demonstrates that the latter may have advantages such as better ventilation and less perioperative bleeding. However, using a nasopharyngeal tube during sedation ensures airway permeability and the increased tendency to bleeding is minimized by the effect of atenolol. A recent study comparing the two techniques showed that local anesthesia has fewer unwanted reflexes, less propensity to arrhythmias or tachycardias, less tendency to vomiting, agitation, and especially fewer lung complications ${ }^{14}$.

In this study, we used low molecular weight heparin at the end of the operation in association with 18$23 \mathrm{mmHg}$ elastic stockings. It is believed that the use of anticoagulants very close to the start of the operation increases the incidence of hematoma ${ }^{1}$. Some authors demonstrated that their use at the end of the operation does not influence operative bleeding 10,15 .

In the sample studied, regardless of whether or not the atenolol was used, there were no coagulation disorders that may have been attributed to the use of anticoagulant. Again, considering age, comorbidities, prevention of venous thrombosis and cardiovascular protection were important points to be preserved.

Several surgical strategies have been used in order to prevent the expanding hematoma, such as the use of a suction drain ${ }^{4}$, but the consensus is that the drains do not prevent nor treat the hematoma ${ }^{3,7}$. Another option is the tumescent infiltration ${ }^{4}$, which reduces the use of adrenaline and "rebound" vasodilation, with the possibility of reducing bleeding and bruising postoperatively. However, if the patient has high blood pressure or heart rate, bleeding may occur ${ }^{16}$. Other strategies, such as external stitches ${ }^{2}$, use of tissue adhesives ${ }^{5}$ and the use of internal adhesion stitches ${ }^{7}$ are mechanical forms to reduce the "dead space", but may not control the bleeding and expanding hemato- 
ma if the patient has a peak of hypertension. Also, mechanical maneuvers may cause retractions or irregularities in the skin ${ }^{8}$. In patients analyzed in this study, we carried out a thorough and careful hemostasis with electrocautery with the patient under local anesthesia and sedation, with BP stable at $120-80 \mathrm{mmHg}$ (and not with induced hypotension) and heart rate 60 bpm. Furthermore, we have used a 3.0 Jackson-Pratt vacuum suction drain and a slightly compressive, occlusive dressing.

The rhytidectomy postoperative pain is generally neglected ${ }^{16}$ and can cause a dangerous cycle consisting of pain, increased blood pressure, nausea and vomiting and may even reach anguish and restlessness, as shown by a study ${ }^{17}$. All these factors may recur and evolve incrementally and even ultimately contribute in important ways to the appearance of expanding hematoma. Patients in this study reported no significant pain in any of the observed times. Even in the four patients in group B who had expansive and hematoma requiring surgical drainage, the report was discomfort and swelling.

Studies ${ }^{3,10,16}$ have systematically related bleeding and expanding hematoma to increased BP. The "reactive hypertension" is described after about three to five hours of facial rhytidectomy, which manifests as increased blood pressure and affects mainly older patients, a group in which this procedure is prevalent ${ }^{16}$.

We believe that there is a "hematoma cycle" in which predisposing factors such as advanced age, propensity to increased blood pressure and preoperative anxiety associated with triggering factors, such as pain, increased blood pressure, vomiting, urinary bladder fullness and psychomotor agitation, can together contribute to the formation of expanding hematoma.

In this context we proposed the use of atenolol, which belongs to the propanolamines group and has antihypertensive and bradycardic action.

An important study analyzing 38,779 operations in 12 years in patients with high surgical risk in other specialty operations clearly demonstrated the benefits of atenolol and the low occurrence of adverse effects ${ }^{18}$. Even being a group of different risk than that of the ones habitually seeking plastic surgery, it is believed that these benefits can be achieved in all medical specialties.

Beta-blockers have been used to induce hypotension and relative bradycardia by intravenous infusion during facial sinuses operations ${ }^{19}$. Another study demonstrated the perioperative efficacy of intravenous betablockers as antiarrhythmics (no depression in myocardial contractility), and in hypertensive response, which occasionally occurs after endotracheal intubation due to reflex tachycardia ${ }^{13}$. The same report showed drastic reduction in perioperative bleeding with preoperative oral beta-blockers. It was shown that beta-2 receptors blockers reduce the production of cytokines by macrophages, attenuating the inflammatory response induced by surgical trauma ${ }^{20}$ Beta-blockers have been used in the prevention of bleeding from esophageal varices, with promising results demonstrated in a meta-analysis ${ }^{21}$

Atenolol shows significant inhibition of the vagal reflexes during stress, its peripheral nervous effect being more important than the central one. Its action starts one hour after the oral use and it has renal excretion, which is not influenced by phenotypes 18,22 . The oral use was for a period of one to 45 days before, and seven days postoperatively, in high-risk patients, at the dose of 25$50 \mathrm{mg}$, displaying success ${ }^{23}$.

In this study, atenolol was used in a protocol that started preoperatively (until $\mathrm{HR}=60 \mathrm{bpm}$ ) and remained until 15 days $\mathrm{PO}$; it was taken once a day, with doses ranging from 25-100 $\mathrm{mg}$, there being no occurrence of expansive hematoma. In the control group, one patient had a hypertensive crisis, with formation of expansive hematoma on the 12th postoperative day. The fact is a justification for the use of atenolol until at least 15 days postoperatively of rhytidectomy.

One patient in group A had significant bradycardia and hypotension in the eighth postoperative day and the medication was suspended, but was not excluded from the present study. Another patient in group A had increased levels of blood glucose after showing symptoms of diabetes on the 15th postoperative day, and the dose of atenolol was reduced to $25 \mathrm{mg} /$ day.

It is estimated that in $25-30 \%$ of overall postoperative periods there is nausea and vomiting ${ }^{17}$; this rate in females is 1.5 to 3.0 times more than in males. As most patients undergoing rhytidectomy are female, we believe it is essential to give them ondansetron in the first 24 hours. Patients observed in this study did not have nausea or vomiting and no symptoms of adverse effect resulting from its use. Even in the four patients in Group B who had expansive hematoma requiring surgical drainage, the presence of this reflex was not observed.

Two authors observed agitation and anxiety in the PO of rhytidoplasties ${ }^{10,24}$. It is believed to be due to anesthesia or related to the the pain cycle. Generally they are associated with increased blood pressure and vomiting, and may contribute to the formation of expansive hematoma. Therefore, clonidine IV to contain the increase in BP has been recommended in the first 24 hours ${ }^{10,24}$. Atenolol was effective to contain the pre-anesthetic reflexes and stop the cycle of pain, controlling high BP and vomiting, due to its action on alpha and beta-1 receptors for a period of at least 15 days ${ }^{12}$.

Bladder plenitude is recognized as an important trigger of discomfort, psychomotor agitation and hypertensive crisis in the perioperative period ${ }^{25}$. The preventive use of urinary Foley catheter in order to continuously empty the bladder and prevent bladder globe was a simple and safe way to reduce the risk of agitation and anxiety and prevent a possible cycle of expansive hematoma. 
Our data suggest that the use of atenolol was effective in controlling the cycle of hematoma in facial rhytidectomy and promote shorter recovery time, decrease the chances of other adverse effects and provide a better cosmetic result. We must, however, emphasize that the other measures associated with pain control, nausea and vomiting, agitation, anxiety and even emptying of the bladder with indwelling catheters were important preventive points in the genesis of hypertension. Studies with larger samples and clinical evaluations of quantitative variables can corroborate more emphatically the information contained herein.

\title{
R E S U M O
}

\begin{abstract}
Objetivo: avaliar o uso perioperatório do atenolol na redução da incidência de hematoma pós-ritidoplastia. Métodos: entre janeiro de 2007 e fevereiro de 2013 foram randomizados 80 pacientes em dois grupos: Grupo A ( $n=26)$ recebeu atenolol perioperatório com objetivo de manter frequência de pulso $(F P) \pm 60$ por minuto, Grupo $B(n=54)$ não recebeu atenolol. Ambos os grupos foram submetidos à mesma técnica anestésico-cirúrgica. A pressão arterial (PA) e FP, formação de hematoma e a necessidade de drenagem foram monitorizados. Houve seguimento até o $90^{\circ}$ dia de pós-operatório. As variáveis foram analisadas entre os dois grupos utilizando-se o teste de ANOVA. As variáveis contínuas foram apresentadas como média \pm Desvio-padrão) e as diferenças foram comparadas utilizando-se o $t$ de Student. Foram considerados significantes os valores $p<0,05$. Resultados: as médias no grupo A de PA $(110-70 \mathrm{mmHg} \pm 7,07)$ e FP $(64 / \mathrm{min} \pm 5)$ foram menores $(p<0,05)$ em relação ao grupo $B(135-90 \mathrm{mmHg} \pm 10,6)$ e $(76 / \mathrm{min} \pm 7,5)$, respectivamente. Houve quatro casos de hematoma expansivo no grupo $B$, todos com necessidade de reoperação para a sua drenagem e nenhum no grupo $A(p<0,001)$. Conclusão: o uso do atenolol perioperatório promoveu a redução de pressão arterial e frequência de pulso e diminuiu a incidência de hematoma expansivo pós-ritidoplastia.
\end{abstract}

Descritores: Antagonistas adrenérgicos beta. Isquemia. Hematoma. Ritidoplastia. Face.

\section{REFERENCES}

1. Durnig P, Jungwirth W. Low-molecular-weight heparin and postoperative bleeding in rhytidectomy. Plast Reconstr Surg. 2006;118(2):502-7; discussion 508-9.

2. Auersvald A, Auersvald LA, Biondo-Simões MAP. Rede hemostática: uma alternativa para a prevenção de hematoma em ritidoplastia. Rev Bras Cir Plast. 2012;27(1):22-30.

3. Grover R, Jones BM, Waterhouse N. The prevention of haematoma following rhytidectomy: a review of 1078 consecutive facelifts. $\mathrm{Br}$ J Plast Surg. 2001;54(6):481-6.

4. Jones BM, Grover R. Avoiding hematoma in cervicofacial rhytidectomy: a personal 8-year quest. Reviewing 910 patients. Plast Reconstr Surg. 2004;113(1):381-7; discussion 388-90.

5. Por YC, Shi L, Samuel M, Song C, Yeow VK. Use of tissue sealants in face-lifts: a metaanalysis. Aesthetic Plast Surg. 2009;33(3):3369.

6. Firmin FO, Marchac AC, Lotz NC. Use of the harmonic blade in face lifting: a report based on 420 operations. Plast Reconstr Surg. 2008;124(1):245-55.

7. Baroudi R, Ferreira CA. Seroma: how to avoid it and how to treat it. Aesthet Surg J. 1998;18(6):439-41.

8. Baker DC, Stefani WA, Chiu ES. Reducing the incidence of hematoma requiring surgical evacuation following male rhytidectomy: a 30-year review of 985 cases. Plast Reconstr Surg. 2005;116(7):1973-85; discussion 1986-7.

9. Zoumalan R, Rizk SS. Hematoma rates in drainless deep-plane face-lift surgery with and without the use of fibrin glue. Arch Facial Plast Surg. 2008;10(2):103-7.

10. Beer GM, Goldscheider E, Weber A, Lehmann K. Prevention of acute hematoma after face-lifts. Aesthetic Plast Surg. 2010;34(4):502-7.

11. Gruber RP, Morley B. Ketamine-assisted intravenous sedation with midazolam: benefits and potential problems. Plast Reconstr Surg. 1999;104(6):1823-5; discussion 1826-7.
12. Apipan B, Rummasak D. Efficacy and safety of oral propranolol premedication to reduce reflex tachycardia during hypotensive anesthesia with sodium nitroprusside in orthognathic surgery: a double-blind randomized clinical trial. J Oral Maxillofac Surg. 2010;68(1):120-4.

13. Jakobsen CJ, Lenler-Petersen P, Blom L. Preoperative adrenergic beta receptor blockade and anesthesia. II. Effect on peroperative anxiety and cardiovascular response in epidural anesthesia. Ugeskr Laeger. 1993;155(29):2269-73.

14. Weise LM, Bruder M, Eibach S, Seifert V, Byhahn C, Marquardt $G$, et al. Efficacy and safety of local versus general anesthesia in stereotactic biopsies: a matched-pairs cohort study. J Neurosurg Anesthesiol. 2013:25(2):148-53.

15. Kim EK, Eom JS, Ahn SH, Son BH, Lee TJ. The efficacy of prophylactic low-molecular-weight heparin to prevent pulmonary thromboembolism in immediate breast reconstruction using the TRAM flap. Plast Reconstr Surg. 2009;123(1):9-12.

16. Berner RE, Morain WD, Noe JM. Postoperative hypertension as an etiological factor in hematoma after rhytidectomy. Prevention with chlorpromazine. Plast Reconstr Surg. 1976;57(3):314-9.

17. Kovac AL. Prevention and treatment of postoperative nausea and vomiting. Drugs. 2000;59(2):213-43

18. Blau WS, Kafer ER, Anderson JA. Esmolol is more effective than sodium nitroprusside in reducing blood loss during orthognathic surgery. Anesth Analg. 1992;75(2):172-8.

19. Shen PH, Weitzel EK, Lai JT, Wormald PJ, Ho CS. Intravenous esmolol infusion improves surgical fields during sevofluraneanesthetized endoscopic sinus surgery: a double-blind, randomized, placebo-controlled trial. Am J Rhinol Allergy. 2011;25(6):e208-11.

20. Rough J, Engdahl R, Opperman K, Yerrum S, Monroy MA, Daly JM. beta2 Adrenoreceptor blockade attenuates the hyperinflammatory response induced by traumatic injury. Surgery. 2009:145(2):235-42

21. Ko SY, Kim JH, Choe WH, Kwon SY, Lee CH. Pharmacotherapy alone vs endoscopic variceal ligation combination for secondary 
prevention of oesophageal variceal bleeding: meta-analysis. Liver Int. 2012;32(5):867-9.

22. Wallace AW, Au S, Cason BA. Perioperative â-blockade: atenolol is associated with reduced mortality when compared to metoprolol. Anesthesiology. 2011;114(4):824-36.

23. Armanious S, Wong DT, Etchells E, Higgins P, Chung F. Successful implementation of perioperative beta-blockade utilizing a multidisciplinary approach. Can J Anaesth. 2003;50(2):131-6.

24. Abu-Shahwan I. Effect of propofol on emergence behavior in children after sevoflurane general anesthesia. Paediatr Anaesth. 2008; 18(1):55-9.

25. Mago AJD, Helayel PE, Bianchini E, Kozuki H, Oliveira Filho GR. Prevalência e fatores preditivos de retenção urinária diagnosticada por ultrassonografia no período pós-anestésico imediato. Rev Bras Anestesiol. 2010;60(4):387-90.
Received on 10/10/2013

Accepted for publication 05/01/2014

Conflict of interest: none.

Source of funding: Medic Trade Body Products Apparel, Aesthetics, Post-Surgical,

Import and Export Ltda.

\section{Mailing address:}

Djalma José Fagundes

E-mail: djfagundes.dcir@epm.br 